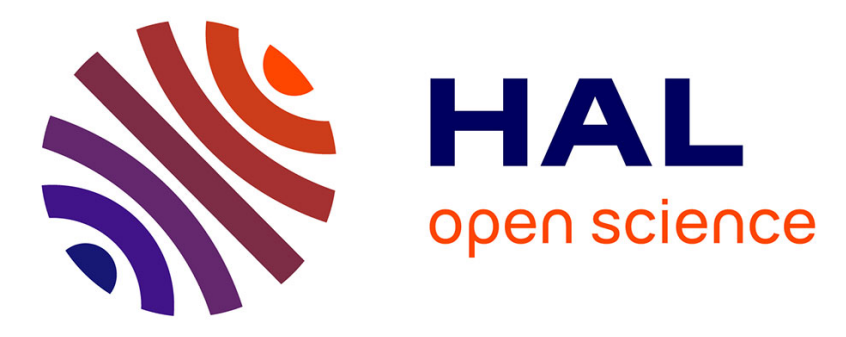

\title{
What Can Be Learned from the Polymerization of a Pyridine-Based Two-Component System
}

Evgenia Vaganova, Faina Dubnikov, Ellina Kesselman, Vladimir Lokshin, Vladimir Khodorkovsky

\section{- To cite this version:}

Evgenia Vaganova, Faina Dubnikov, Ellina Kesselman, Vladimir Lokshin, Vladimir Khodorkovsky. What Can Be Learned from the Polymerization of a Pyridine-Based Two-Component System. Macromolecular Symposia, 2019, 385 (1), pp.1800157. 10.1002/masy.201800157 . hal-02376296

\section{HAL Id: hal-02376296 \\ https://hal.science/hal-02376296}

Submitted on 22 Dec 2021

HAL is a multi-disciplinary open access archive for the deposit and dissemination of scientific research documents, whether they are published or not. The documents may come from teaching and research institutions in France or abroad, or from public or private research centers.
L'archive ouverte pluridisciplinaire HAL, est destinée au dépôt et à la diffusion de documents scientifiques de niveau recherche, publiés ou non, émanant des établissements d'enseignement et de recherche français ou étrangers, des laboratoires publics ou privés. 


\section{What can be learned from the polymerization of a pyridine - based two-component system}

Evgenia Vaganova, ${ }^{* 1}$ Faina Dubnikov, ${ }^{1}$ Ellina Kesselman, ${ }^{2}$ Vladimir Lockshin, ${ }^{3}$ Vladimir Khodorkovsky*3

${ }^{1}$ The Institute of Chemistry, The Hebrew University, The Edmond J. Safra Campus - Givat Ram, Jerusalem 9190401, Israel; E-mail:evgenia@mail.huji.ac.il

${ }^{2}$ Faculty of Chemical Engineering, Technion - Israel Insitute of Technology, Haifa 3200003, Israel

${ }^{3}$ Aix Marseille Université, CNRS, CINaM UMR 7325, 13288, Marseille, France; E-mail: khodor@cinam.univ-mrs.fr

Summary: Stable poly(4-vinyl pyridine)/pyridine gels prepared by dissolving solid polymer in pyridine (the equimolar ratio of the pyridine moieties to the pyridine solvent molecules) exhibit sensor properties rapidly and reversibly increasing their conductivity upon irradiation by light in the UV-Vis and NIR ranges. Both ionic and electronic mechanisms of conductivity were detected. The gels behave as polyelectrolytes involving the positively charged pyridine moieties and negatively charged saturated chains held together by a network of hydrogen bonds between the charged and neutral species. This interpretation is corroborated by the cryo -TEM images of the gel samples resembling chains of beads and the analysis of FT-IR and ${ }^{1} \mathrm{H}-\mathrm{NMR}$ spectra. Photoinduced proton transfer can thus be responsible for the observed ionic conductivity of the gels. Exposing gels to the ambient light can bring about pyridine moieties and molecules ring opening with subsequent polycondensation of the initially formed 5-amino-2,4-pentadienal. The oligomers of the latter, aza-analogs of polyacetylene, can serve as molecular wires providing the electronic component of electrical conductivity. These oligomers can also contribute to the ionic conductivity and further stabilize the gels by cross-linking of the separate polymer chains.

Keywords: gel; polyelectrolyte, open-chain oligomerization; cryo-TEM; NMR 


\section{Introduction}

Polymers exhibit a diversity of charge transfer mechanisms combining delocalization and localization of charge carriers with intra- and intermolecular interactions. ${ }^{[1]}$ Different types of conductivity involving electronic, ionic and charge transfer can give rise to a variety of physical and chemical properties, especially in soft materials. ${ }^{[2]}$ The conductivity phenomena within polymers can be employed in several types of devices, such as optical sensors, memory storage, energy harvesting, mechanical devices, etc.

Recently, poly(4-vinyl pyridine)/pyridine (P4VPy/Py) blends attract attention owing to their unusual sensor properties. The P4VPy/Py gels doped with a polymer, containing the ester groups, exhibit very high sensitivity to radiation in a wide range of wavelength, from UV to NIR (up to 10$12 \mu \mathrm{m}) .{ }^{[3]}$

Doping the same polymeric composition by polymers involving the carboxylic groups, expands the range of the gel photoelectrical sensitivity further in NIR with markedly different relaxation times. ${ }^{[4]}$

These polymer blends are optimized versions of the initial two-component composition: poly(4-vinyl pyridine), dissolved in pyridine with equimolar ratio of the pyridine moieties to the solvent molecules. ${ }^{[5-7]}$ This mixture forms a gel upon storing about one week.

Here we summarize what is known about the properties of P4VPy/Py gels, ${ }^{[5-10]}$ and present some recent results that can shed light on the origins of high sensitivity of such gels to irradiation and discuss possible mechanisms of their unusually high electrical conductivity.

Our research on the P4VPy/Py gels showed that the two types of conductivity are responsible for their behavior: ionic and electronic. ${ }^{[10]}$ We have demonstrated that the gel contains multiple forms of hydrogen bonding owing to the self-protonation of the pyridine moieties by protons originating from the $\mathrm{CH}$ group of the polymer main chain. ${ }^{[8]}$ The photoinduced zwitterions formation and proton transfer by liquid pyridine molecules was proved experimentally by solid state NMR N ${ }^{15}$ of the enriched polymer gel by the group of Prof. Limbach and rationalized by quantum mechanical calculations on the DFT level ${ }^{[9]}$ However, the origin of the electronic conductivity the enriched polymer gel by the group of Prof. Limbach and rationalized by quantum mechanical 
calculations on the DFT level. ${ }^{[9]}$ However, to date, the origin of the electronic conductivity remained unknown, and we have been unable to adequately explain the gel's remarkably flexible response to external perturbation. ${ }^{[10]}$

Indeed, even the initial two-component gel was shown to be photo/electro sensitive: the gel response by $\mathrm{pH}$, luminescence, electrical conductivity upon irradiation at $385 \mathrm{~nm}$ was observed without any additional doping. Thus, the measured proton mobility in the P4VPy/Py gel was about $1.8 \times 10^{-3} \mathrm{~cm}^{2} \mathrm{~V}^{-1} \mathrm{~s}^{-1}$, similar to proton mobility in ice, whereas the electron mobility of $25 \mathrm{~cm}^{2} \mathrm{~V}^{-}$ ${ }^{1} \mathrm{~s}^{-1}$ was measured, ${ }^{[10]}$ higher significantly higher than $\sim 0.45-0.85 \mathrm{~cm}^{2} \mathrm{~V}^{-1} \mathrm{~s}^{-1}$ detected in semiconducting polymer. ${ }^{[11]}$

To gain deeper insight into the morphology of the gels and the nature of active species we studied cryo-TEM imaging, FTIR, NMR and DFT calculations. We demonstrated that the gel behaves a polyelectrolyte involving the protonated pyridine moieties (positive charge) and the negative charge ${ }^{[8,10]}$ localized on a main saturated chain. In addition, magnetic susceptibility measurements on the irradiated gel shows the Curie constant corresponding to an effective magnetic moment of $0.2 \mu_{\mathrm{B}} / \mathrm{mol}$, meaning that, on average, one unpaired electron is present on one of five vinyl pyridine units. ${ }^{[10]}$ Polyelectrolyte properties are shown by the morphology study with the cryoTEM assistance. We also demonstrated that the ring opening of pyridine or/and the pyridine moieties occurs on light with the formation of 5-amino-2,4-pentadienal, polycondensation of which can afford the electron accepting and electron conductive wires in the gel. 


\section{Cryo TEM investigation: spontaneously formed polyelectrolyte.}

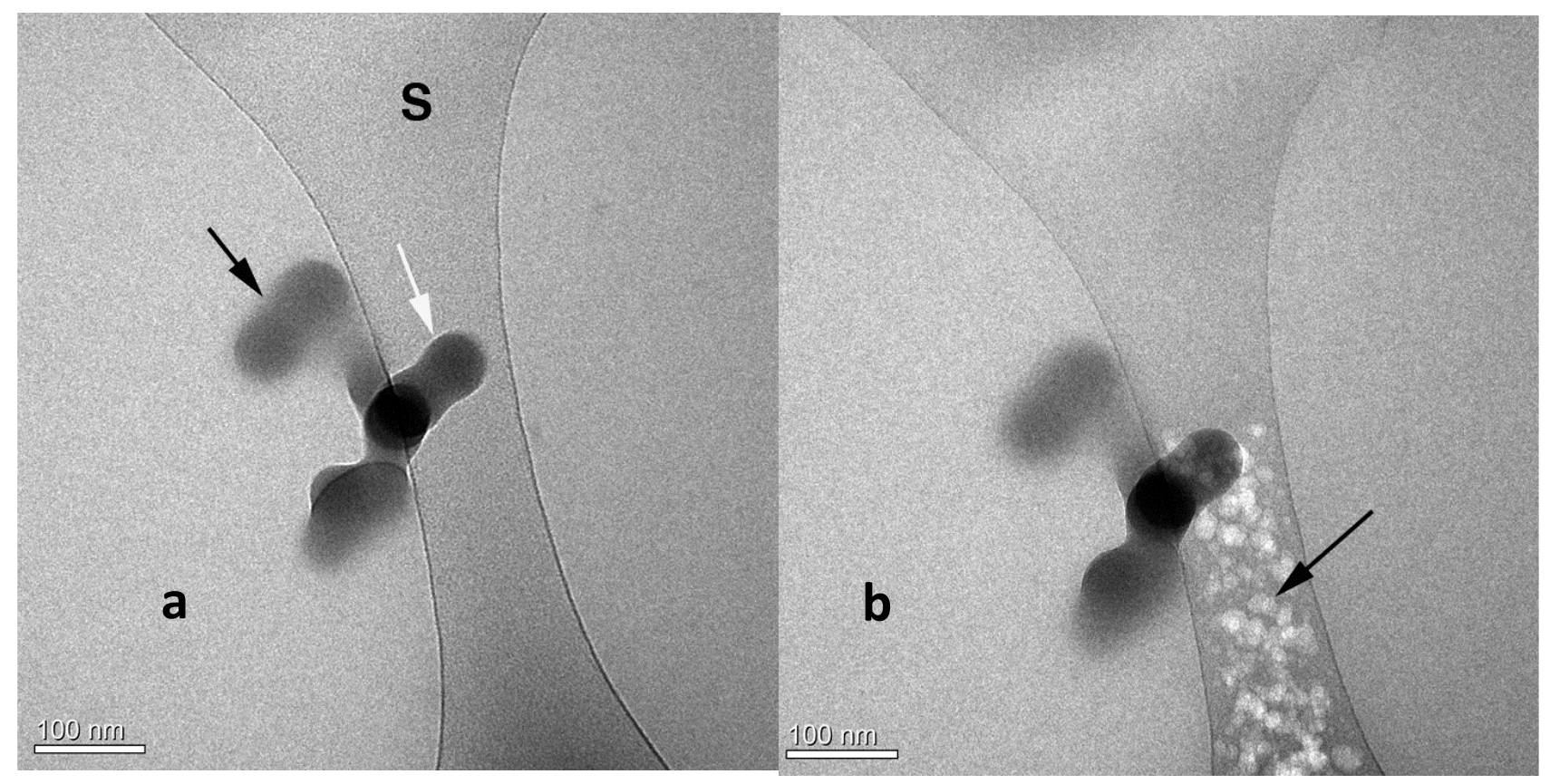

Figure 1. The cryo-TEM images of P4VPy/Py gel aggregates: low electron dose (a) and the same area at a high electron does (b) irradiation. (S) is only a support film.

P4VPy gel solutions were examined by cryo-TEM.

Figure 1 presents typical cryo-TEM image of P4VPy/Py gel aggregates. The black arrow in micrograph (a) indicates a part of the aggregate that is embedded in the vitreous ice, while the part indicated by a white arrow is out of the ice matrix, (S) marked a support film. In frame (b) we see damage to the support film (arrow), but non-visible on the aggregate, which indicates that it's not surface contaminations.

The aggregates of P4VPy/Py gel (Figure 1) exhibit strong resemblance to chains of beads. ${ }^{[12]}$ The single bead diameter about $130 \mathrm{~nm}$ had been measured and practically does not change. (For comparison, the hydrodynamic radius of a P4VPy molecule in ethanol is about $14 \mathrm{~nm}) .{ }^{[7]}$ 
The condensation of polymer molecules in beads is a well-known property of polyelectrolytes. ${ }^{[12]}$ It occurs owing to the electrostatic interaction of polycations, the protonated pyridine molecules/moieties and polyanions, the negatively charged main chain. ${ }^{[8]}$ The self-protonation of P4VPy was already demonstrated earlier. ${ }^{[13]}$ The Cryo-TEM images confirm the polyelectrolyte formation occurring in bulk.

\section{IR spectra: weakly bound zwitterion/pyridine complexes.}

IR spectra of P4VPy solutions in different solvents are presented in Figure 2. In all solvents and in a solid film a broad band about $3400 \mathrm{~cm}^{-1}$ is observed and it is the most intense in pyridine and DMSO solutions. In chloroform and methylene chloride solutions this band is relatively less intense and an additional band about $2970 \mathrm{~cm}^{-1}$ appeared in the spectra. This band can be assigned to the stretching mode of chloroform and methylene chloride $\mathrm{C}-\mathrm{H}$ bonds forming the hydrogen bond with pyridine nitrogen of P4VPy. 


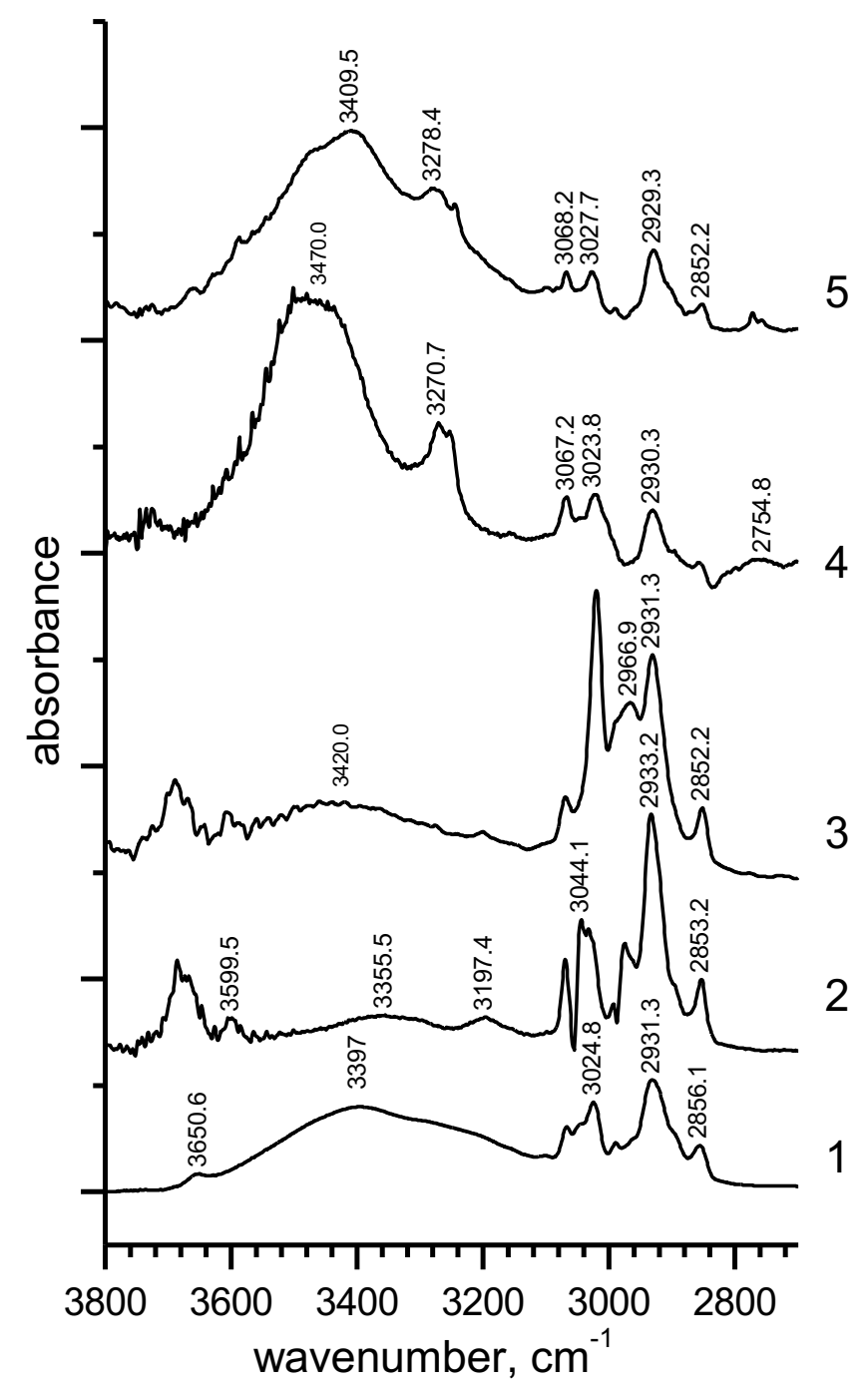

Figure 2. IR spectra of pure P4VPy: 1. a film from $\mathrm{CD}_{2} \mathrm{Cl}_{2} ;$ solutions in 2. $\mathrm{CD}_{2} \mathrm{Cl}_{2} ; 3 . \mathrm{CDCl}_{3} ; 4$. $\left(\mathrm{CD}_{3}\right)_{2} \mathrm{SO} ; 5 . \mathrm{C}_{5} \mathrm{D}_{5} \mathrm{~N}$.

All new results confirm our previous assumption ${ }^{[13]}$ that the band at $3400 \mathrm{~cm}^{-1}$ belongs to the stretching proton mode of the $\mathrm{P} 4 \mathrm{VPy}$ side chain cation $\mathrm{PyH}^{+}$, which is formed after self-protonation of P4VPy, i.e. after a part of $\mathrm{C}-\mathrm{H}$ protons transfers onto the pyridine nitrogen atom without doping by an acid. The same position of the band around $3400 \mathrm{~cm}^{-1}$ in solid film, methylene chloride and chloroform supports its assignment to the $\mathrm{PyH}^{+}$species. In pyridine and DMSO solution the band position is shifted and appears at about $3280 \mathrm{~cm}^{-1}$. ${ }^{[14]}$ From the red shift of this band the H-bond energy between $\mathrm{PyH}^{+} \cdots$ Py can be estimated as $12.4 \mathrm{~kJ} \cdot \mathrm{mol}^{-1} .{ }^{[15]}$ The band at $3400 \mathrm{~cm}^{-1}$ is always present in the spectra of P4VPy (and P2VPy) when both polymers are of an acid or the polymer was 
recrystallized from any solvent. ${ }^{[14-18]}$ It should be stressed that although this band in methylene chloride and chloroform solutions is relatively weak, the solid film of P4VPy after precipitation from methylene chloride exhibits considerably higher intensity band (Figure 2, trace 1).

\section{${ }^{1} \mathrm{H}-\mathrm{NMR}$ spectra of pure P4VPy solutions: singlet resonance signal at $\mathbf{1 0 . 5} \mathbf{~ p p m}$ inherent property of a gel.}




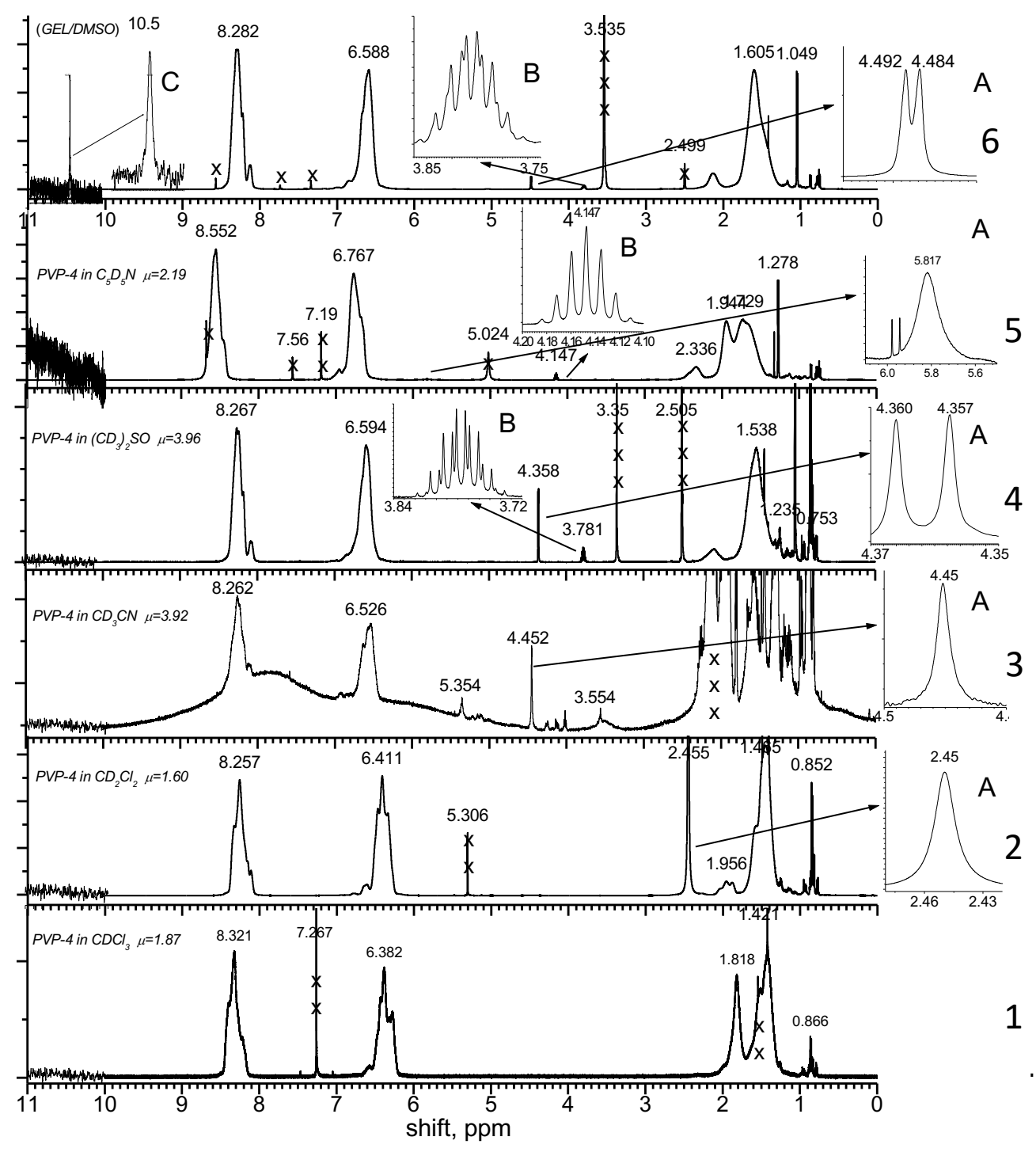

Figure 3. ${ }^{1} \mathrm{H}-\mathrm{NMR}$ spectra of pure P4VPy powder in solvents: $1-\mathrm{CDCl}_{3} ; 2-\mathrm{CD}_{2} \mathrm{Cl}_{2} ; 3-\mathrm{CD}_{3} \mathrm{CN}$ ; 4 - $\left(\mathrm{CD}_{3}\right)_{2} \mathrm{SO} ; 5-\mathrm{C}_{5} \mathrm{D}_{5} \mathrm{~N} ; 6-\mathrm{Gel} \mathrm{P} 4 \mathrm{VP} / \mathrm{C}_{5} \mathrm{D}_{5} \mathrm{~N} /\left(\mathrm{CD}_{3}\right)_{2} \mathrm{SO}$. The signals of H-solvents and watersolvent complexes are labeled with crosses.

The ${ }^{1} \mathrm{H}-\mathrm{NMR}$ spectra of P4VPy in different solvents are shown in Figure 3. A narrow singlet signal is observed in methylene chloride- $d_{2}(2.45 \mathrm{ppm})$, acetonitrile- $d_{3}(4.45 \mathrm{ppm})$, and pyridine- $d_{5}(5.82$ ppm) solutions of P4VPy. In DMSO- $d_{6}$ solution the new doublet signals at 4.38/4.36 ppm (4), 4.49/4.48 ppm (6) doublet, and signal methine proton signal at $3.78 \mathrm{ppm}$ are observed. ${ }^{1} \mathrm{H}-\mathrm{NMR}$ spectrum of the gel, dissolved in DMSO- $d_{6}$, reveals a new singlet at $10.5 \mathrm{ppm}$. For no other P4VPy sample is a resonance observed in this spectral range. 
The additional new signals observed in P4VPy/Py and gel P4VPy/Py(1:1)/DMSO) solutions shift downfield and become narrower on decreasing the temperature (Figure 4).

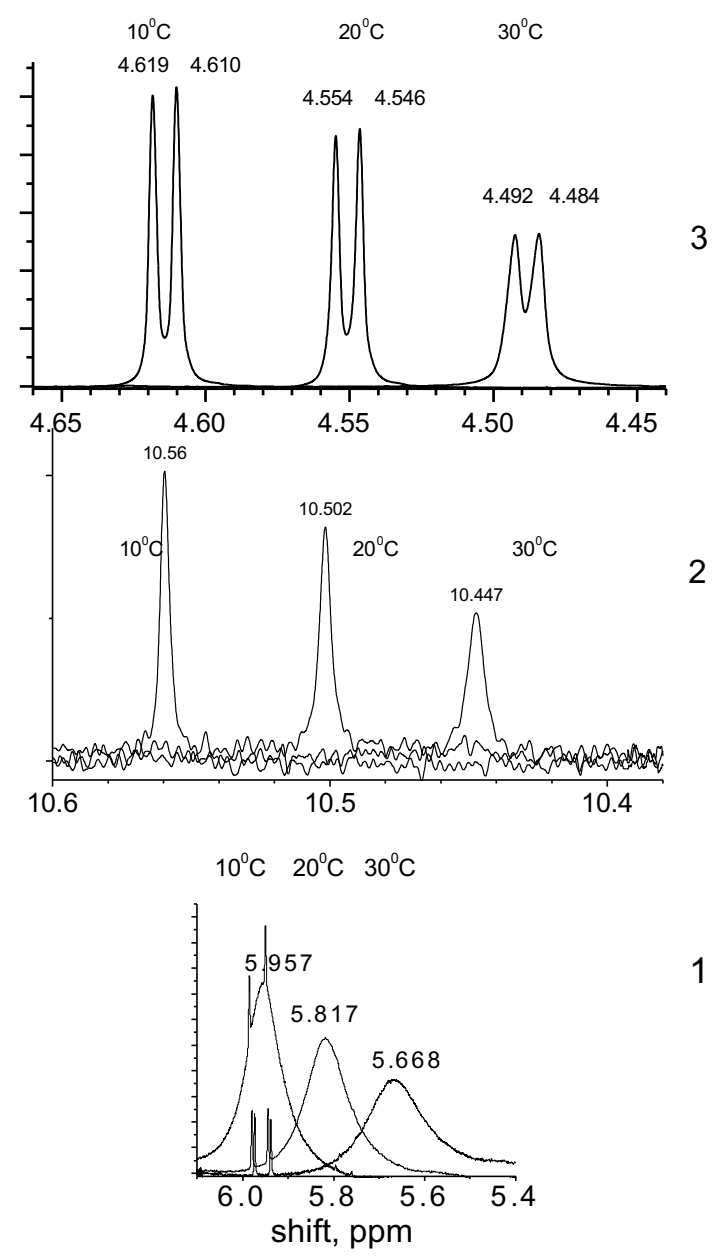

Figure 4. Temperature dependence of the ${ }^{1} \mathrm{H}-\mathrm{NMR}$ signals of P4VPy: 1: solution in pyridine- $d_{5}, 2$ and 3: gel $\mathrm{P} 4 \mathrm{VPy} / \mathrm{C}_{5} \mathrm{D}_{5} \mathrm{~N}$ in DMSO- $d_{6}$.

Such sensitivity to changes in temperature is characteristic of protons participating in intermolecular interactions; other proton resonances are comparatively not affected.

\section{Photoinduced pyridine oligomerization.}


Whereas photochemistry of P4VPy films exposed to UV irradiation at $250-270 \mathrm{~nm}$ has been studied, the spectroscopic changes observed during irradiation were poorly documented, ${ }^{[19]}$ the second component of the gels, pyridine itself and its solutions, may behave differently. The instability of pyridine upon storing on ambient light indicated by appearance of yellow to brownish coloration is well known. Pyridine was shown to produce 5-amino-2,4-pentadienal upon irradiation at $254 \mathrm{~nm} \cdot{ }^{[20-21]}$ This compound is unstable and reverts slowly to pyridine in the dark and cannot be responsible to pyridine coloration. We found that irradiation of neat pyridine leads to the formation of the ring-opened product also at higher wavelengths (e.g. at 312 or $405 \mathrm{~nm}$ ) and is not fully reversible. Thus, whereas the absorption of 5-amino-2,4-pentadienal at about $360 \mathrm{~nm}$ disappears in dark, noticeable, albeit weak, absorption in the visible range persists.

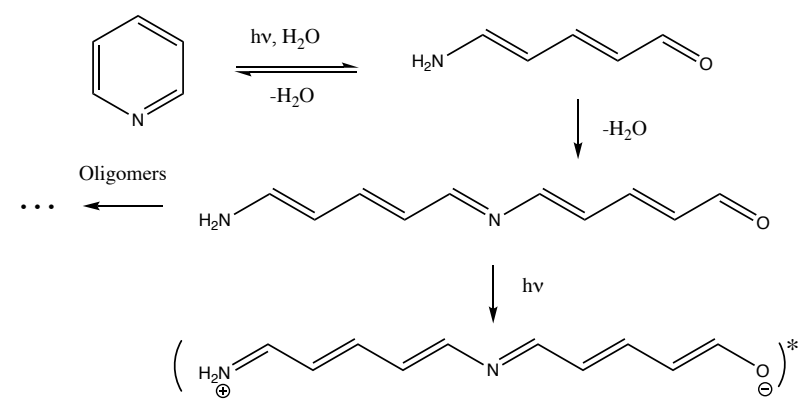

Scheme 1. Pyridine photochemical ring opening and polycondensation.

Freshly distilled pyridine samples, which still contain some water that is difficult to completely remove owing to the hygroscopicity of pyridine, are especially sensitive to irradiation. Monitoring the reaction by fluorescence showed rapid appearance of several fluorescence bands or shoulders at about 450, 505, 530, 560 and $620 \mathrm{~nm}$, depending on the excitation wavelengths. (Figure 5). Samples absorption extends up to $600 \mathrm{~nm}$ and both absorption and fluorescence of the irradiated samples does not change upon storing in dark for several weeks. The fluorescence spectra strongly resemble emission observed from irradiated P4VPy/Py gel. ${ }^{[22]}$ 


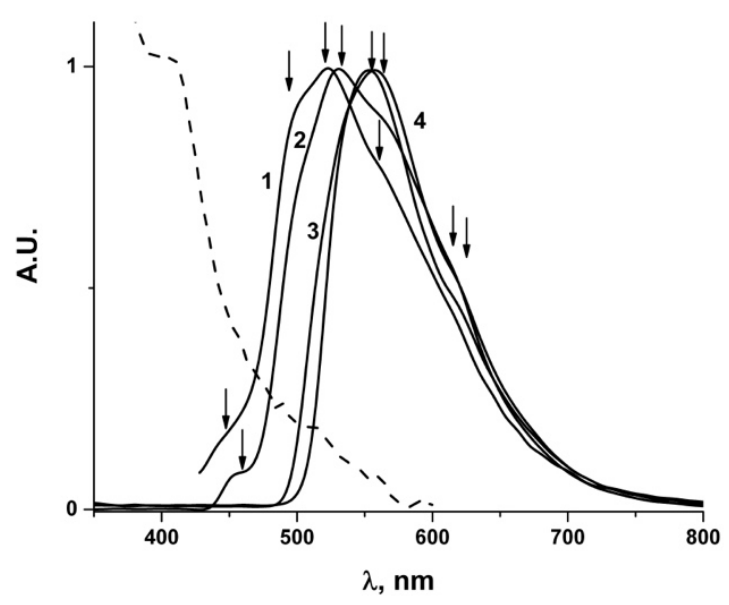

Figure 5. Normalized fluorescence spectra of pyridine irradiated at $312 \mathrm{~nm}$ during $10 \mathrm{~min}$. Excitation wavelengths: 1) $405 \mathrm{~nm}$; 2) $450 \mathrm{~nm}$; 3) $505 \mathrm{~nm}$;) $525 \mathrm{~nm}$. Dashed curve: absorption spectrum.

Oligomers of 5-amino-2,4-pentadienal, which are actually aza analogs of polyacetylene, can serve as molecular wires responsible for the electronic conductivity. At the same time, the presence of the conjugated D- $\pi$-A chains can contribute to the ionic conductivity of the gels on light, as these systems are stronger bases in their excited states owing to charge transfer $\left(D^{+}-\pi-A^{-}\right)$.

After several hours of irradiation, a semi-solid poorly soluble yellow-brown precipitate formed. It is currently under investigation.

\section{Conclusions}

The investigations on the P4VPy/Py gels spanning several years led to the development of new materials extremely sensitive in a broad wavelength range: from UV-Vis up t0 NIR (about 10-12 $\mu \mathrm{m}$ ), with unusually rapid response and high electrical conductivity of the materials. Self-aggregation of P4VPy solutions in pyridine occurs on light owing to light-induced proton transfer and stabilization of the charged species by the network of hydrogen bonds. At the same time, the ring opening of several the pyridine moieties and free pyridine molecules and further oligomerization of the intermediate can produce fully conjugated species contributing 
to both the electronic and ionic conductivity. The formation of oligomers absorbing and emitting light in the visible and IR range can account for the sensitivity of the materials based on the P4VPy/Py gels. This aspect of the possible mechanism of the sensing P4VPy/Py gel properties is currently under investigation in our research labs.

\section{Acknowledgements:}

Financial support for this work was received from Yissum (HUJI). EV thanks the Israel Ministry of Absorption for financial support; Prof. S Yitzchaik (HUJI) for collaboration and assistance, Dr. M. Rozenberg (HUJI) for the measurements and discussions, Prof. I. Talmon (Technion) for cryo-TEM experiments, students: E. Mervenetsky, A. Gankin, V. Tolstenkova, F. Melhem (HUJI) for experiments with gels. Dr. E. Wachtel (WIS) for many years scientific support.

\section{References:}

[1] R.J. Fleming, Brazilian Journal of Physics, 1999, 29, 280.

[2] T. Kato, N. Miroshita, K. Kishimoto, Angewante Chemie, 2006, 45, 38.

[3] E. Vaganova, E. Wachtel, A. Goldberg, S. Yitzchaik, J. of Phys. Chem. C,

2012, 116, 25028.

[4] E. Vaganova, "A bi-functional Bolometer with Sensitivity to IR Radiation and Hot Air Induced Temperature Variation”, EM -ThP5, p. 153, AVS 63 ${ }^{\mathrm{RD}}$ International Symp. \& Ex., November 6-11, 2016, Nashville, US.

[5] E. Vaganova, M. Rozenberg, S. Yitzchaik, Chem. of Mat., 2000, 12, 260.

[6] E.Vaganova, G., Meshulam, Z. Kotler, M. Rozenberg, S. Yitzchaik, J. Fluorescence, 2000, 10, 81.

[7] E. Vaganova, S. Yitzchaik, Macromol. Symposia_ 2004, 207, 95.

[8] E. Vaganova, M. Rozenberg, F. Dubnikova, D. Danovich, S.Yitzchaik, New J. Chem. 2015, 39, 5920.

[9] E. Vaganova, E. Wachtel, G. Leitus, D. Danovich, S. Lesnichin, I. Shenderovich, Hans-Henrich Limbach, S. Yitzchaik, J. Phys. Chem. B, 2010, 114, 10728.

[10] N. Berestetsky, E. Vaganova, E. Wachtel, G. Leitus, A. Goldberg, S. Yitzchaik, J.Phys. Chem. B, 2008, 112, 3662.

[11] H. Yan, Z. Chen, Y. Zheng, C. Newman, J.R. Quinn, F. Dötz, M. Kastel, A. Facchetti, Nature, 2009, 457, 679 .

[12] R.S. Diass, A.A.C.C. Pais, Advances in Colloid and Interface Science, 2010, 158, 48.

[13] M. Rozenberg, E. Vaganova and S. Yitzchaik, New J. Chem. 2000, 24, 109.

[14] A.V. Iogansen, Spectrochim. Acta, 1999, 55A, 1585.

[15] N. Sahiner, S. Yildiz, Fuel Processing Technology, 2014, 126, 324.

[16] P. Chetri, N.N. Dass, N.S. Sarma, Mat. Sci. and Eng. B, 2006, 128, 188.

[17] P. Chetri, N.N. Dass, N.S. Sarma, J. Appl. Polymer Science, 2009, 112, 1444.

[18] R. Narayan, P. Kumar, K.S.Narayan, S.K. Asha, J. Mater. Chem. C. 2014, 2, 6511.

[19] M. I. Avadanei, V. Barboiu, C. Luca, J. of Photochemistry and Photobiology A: Chemistry, 2009, 207, 260 and references therein.

[20] K. E. Wilzbach, D. J. Rausch, J. Am. Chem. Soc., 1970, 92, 2178.

[21] J. C. Andre, M. Niclause, J. Joussot-Dubien, X. Deglise, J. Chem. Educ., 1977, 54, 387 and references therein

[22] E. Vaganova, C. Damm, G. Israel, S. Yitzchaik, J. Fluorescence, 2002, 12, 219. 